\title{
PREVENTION OF THE HYPOXIC REOXYGENATION INJURY WITH THE USE OF A LEUKOCYTE-DEPLETING FILTER
}

Kirk S. Bolling, MD, MPH*

Ari Halldorsson, MD

Bradley S. Allen, MD

Shaikh Rahman, MS

Tingrong Wang, MD

Michael Kronon, MD**

Harold Feinberg, PhD
Objectives: Recent studies have shown that an injury occurs when the hypoxic heart is suddenly reoxygenated (as occurs with cardiopulmonary bypass), resulting in myocardial depression, impaired oxygenation, and increased pulmonary vascular resistance. We hypothesize that this injury is, in part, due to oxygen-derived radicals produced by activated white cells and may therefore be ameliorated by limiting leukocytes in the bypass circuit. Methods: Fifteen neonatal piglets underwent 60 minutes of ventilator hypoxia (inspired oxygen fraction $8 \%$ to $10 \%$ ), followed by reoxygenation with cardiopulmonary bypass at an inspired oxygen fraction of $100 \%$ for 90 minutes. In nine piglets (group 1) our routine bypass circuit was used with no modifications, and in six piglets (group 2) a leukocyte-depleting filter (Pall BC-1; Pall Biomedical Products Corporation, Glencoe, N.Y.) was inserted in the arterial line to lower the neutrophil count. Six additional piglets underwent 90 minutes of bypass without hypoxia (cardiopulmonary bypass controls). Postbypass myocardial and pulmonary function was assessed by pressure volume loops, arterial/alveolar ratio, and pulmonary vascular resistance index. Results are expressed as a percentage of control. Results: By comparison with group 1 piglets (reoxygenation without a filter), hypoxic piglets undergoing reoxygenation with a leukocyte-depleting filter (group 2) had improved myocardial systolic function $(88 \%$ vs $52 \%$; $p<$ $0.05)$, diastolic compliance $(175 \%$ vs $275 \% ; p<0.05)$, and preload recruitable stroke work $(91 \%$ vs $54 \% ; p<0.05)$; had better preservation of the arterial/alveolar ratio $(97 \%$ vs $74 \% ; p<0.05)$; and had less increase in pulmonary vascular resistance $(229 \%$ vs $391 \%$; $p<0.05)$. Furthermore, leukocyte filtration prevented adenosine triphosphate depletion or a change in tissue antioxidants. Conversely, unprotected piglets (group 1) exhibited lower levels of adenosine triphosphate and significant loss of tissue antioxidants. Indeed, the results in the leukocyte-filtered piglets (group 2) were nearly identical to those of piglets subjected to bypass without hypoxia (controls). Conclusions: (1) This study demonstrates that a major component of the injury that occurs when the hypoxic heart is abruptly reoxygenated is caused by oxygen radicals produced by white blood cells; (2) this injury can be prevented by a leukocyte-depleting filter; and (3) avoidance of this injury improves postbypass myocardial and pulmonary function. These data suggest that leukocyte depletion should be used routinely in all children undergoing operations for cyanotic heart disease or extracorporeal membrane oxygenation. (J Thorac Cardiovasc Surg 1997;113:1081-90)
From the Division of Cardiothoracic Surgery, The University of Illinois, Chicago, IIl.

Read at the Twenty-first Annual Meeting of The Western Thoracic Surgical Association, Coeur d'Alene, Idaho, June 21-24, 1995.

Received for publication August 15, 1996; revisions requested Jan. 30, 1997; revisions received Feb. 17, 1997; accepted for publication Feb. 18, 1997.
Address for reprints: Bradley S. Allen, MD, University of Ilinois, Cardiothoracic Surgery Department, 840 S. Wood St., 515 CSN (M/C 958), Chicago, IL 60612.

*Samson Award Finalist.

**Supported in part by the Pillsbury Fellowship.

Copyright (C) 1997 by Mosby-Year Book, Inc.

$0022-5223 / 97 \$ 5.00+0 \quad \mathbf{1 2 / 6 / 8 1 2 5 0}$ 
$R^{c}$ epair of cyanotic heart defects necessitating cardiopulmonary bypass (CPB) is becoming more frequent in infants and neonates. Despite apparently successful surgical correction, postoperative myocardial dysfunction continues to be problematic and is a major cause of morbidity and mortality. 1,5 Recent clinical findings document that chronic cyanosis depletes the myocardium of endogenous antioxidants, and a growing body of experimental and clinical evidence indicates that this may make the cyanotic immature heart more susceptible to an oxygen-mediated injury when molecular oxygen is restored., 6,9 In addition, the polymorphonuclear leukocyte is widely believed to be a major contributor to this reoxygenation injury because of its production of oxygen-derived free radicals. ${ }^{10-13} \mathrm{Al}-$ though the neonatal heart is more tolerant to reduced levels of oxygen than the adult, it has less systolic and diastolic reserve and is also less responsive to inotropic intervention. $3,4,14,15$ In light of these facts, preservation of cardiac function is even more important in the neonate, because a perioperative insult is less well tolerated and more difficult to treat. $^{3,4,14}$ Therefore, if the cyanotic neonatal myocardium is susceptible to a reoxygenation injury during reintroduction of molecular oxygen, and this damage is produced by oxygen-derived free radicals, it may be possible to minimize the reoxygenation injury through the use of a leukocyte filter, because white cells are a primary source of oxygen radicals. This study tests this hypothesis by examining the effects of reoxygenating the hypoxic myocardium using CPB, with and without a leukocyte-depleting filter.

\section{Material and methods}

Twenty-one neonatal piglets ( 5 to 18 days old; 3.5 to 5 $\mathrm{kg}$ ) were premedicated with ketamine, $40 \mathrm{mg} / \mathrm{kg}$ given intramuscularly, and anesthetized with pentobarbital, 30 $\mathrm{mg} / \mathrm{kg}$ given intraperitoneally and followed by $5 \mathrm{mg} / \mathrm{kg}$ given intravenously each hour. The lungs were ventilated via a tracheotomy with a volume ventilator (Servo 900B Siemens-Elema, Solna, Sweden). All animals received humane care in compliance with the "Principles of Laboratory Animal Care" formulated by the National Society for Medical Research and the "Guide for the Care and Use of Laboratory Animals" prepared by the National Academy of Sciences and published by the National Institutes of Health (NIH Publication No. 96-03, revised 1996).

The femoral artery and vein were cannulated to monitor arterial pressure, for blood gas determinations, and for intravenous infusions. The heart was exposed by a median sternotomy, and transducer-tipped catheters (Miller Instruments, Inc., Houston, Tex.) were placed into the left ventricle (LV), thoracic aorta (via the thoracic artery), left atrium, and pulmonary artery. The signals were routed to a recorder (model $4586 \mathrm{C}$, Hewlett-Packard Company, Palo Alto, Calif.) via signal conditioners (model 8805C, Hewlett-Packard). An eight-electrode equipped conductance catheter (Webster Laboratories, Baldwin Park, Calif.) was inserted through the LV apex and connected to a Sigma-5-DF signal conditioner processor (Leycon, Oegstgeest, The Netherlands).

After system heparinization ( $3 \mathrm{mg} / \mathrm{kg}$ ), a thin-walled venous cannula $(18 \mathrm{~F})$ and an aortic cannula $(8 \mathrm{~F})$ were inserted into the right atrial appendage and left subclavian artery, respectively. Arterial blood gases, electrolytes, and hemoglobin (Blood Gas System 288, Ciba Corning, Medfield, Mass.) were measured every 5 to 15 minutes to ensure optimum levels. A heating blanket was placed below the piglet and a heating pad was placed on the abdomen to keep rectal temperature $37^{\circ}$ to $38^{\circ} \mathrm{C}$. The CPB circuit was heparinized, primed with packed red cells from donor pigs, and made normocalcemic with calcium chloride. The hematocrit value was adjusted to $25 \%$ to $35 \%$ with $0.9 \%$ normal saline solution (Baxter Healthcare Corp., Deerfield, Ill.). A Shiley Plexus membrane oxygenator (Shiley, Inc., Irvine, Calif.) was used and aortic pressure kept between 40 and $50 \mathrm{~mm} \mathrm{Hg}$ by adjustment of systemic flow to approximately $100 \mathrm{ml} / \mathrm{kg}$ per minute. Piglets were observed for 60 minutes after CPB, while arterial blood gas and electrolyte levels were normalized. Final measurements of contractile and pulmonary function were made 30 and 60 minutes after discontinuing $\mathrm{CPB}$. Hearts were then arrested with cold $\left(4^{\circ} \mathrm{C}\right)$ blood cardioplegia to stop metabolism and a transmural $\mathrm{LV}$ biopsy sample was obtained. The endocardial and epicardial portions were separated, frozen quickly in liquid nitrogen, and stored for biochemical analysis.

Physiologic determinations. Total white blood cell (WBC) (Sysmex K1000; Baxter) and neutrophil (manual differential) counts were determined before CPB; at 5, 60, and 90 minutes of $\mathrm{CPB}$; and 30 minutes after CPB. Hemodynamic and pulmonary measurements were made before hypoxia or bypass (CPB control), at the end of hypoxia, and 30 and 60 minutes after CPB was discontinued. Cardiac output was determined with the use of the conductance catheter. Cardiac index $(\mathrm{Cl})$, pulmonary vascular resistance index (PVRI), and arterial/alveolar (a/A) ratio were calculated by the following equations:

$$
\begin{gathered}
\text { CI }=\text { CO } / \mathrm{BSA} \\
\text { PVRI }=\frac{\text { PAP }- \text { LAP }}{\mathrm{CI}} \times 80
\end{gathered}
$$

$\mathrm{a} / \mathrm{A}$ tension ratio

$$
=\frac{\mathrm{PO}_{2}}{\mathrm{FiO}_{2}\left(\mathrm{P}_{B}-\mathrm{PH}_{2} \mathrm{O}\right)-\overline{\mathrm{PCO}_{2}\left(1.25-0.25 \mathrm{FiO}_{2}\right)}}
$$

where PAP is mean pulmonary artery pressure, LAP is mean left atrial pressure, BSA is body surface area, $\mathrm{CO}$ is cardiac output in milliliters per minute, $\mathrm{PO}_{2}$ is partial pressure of oxygen, $\mathrm{FiO}_{2}$ is inspired percentage of oxygen, $\mathrm{PCO}_{2}$ is partial pressure of carbon dioxide, $\mathrm{PB}$ is barometric pressure, and 


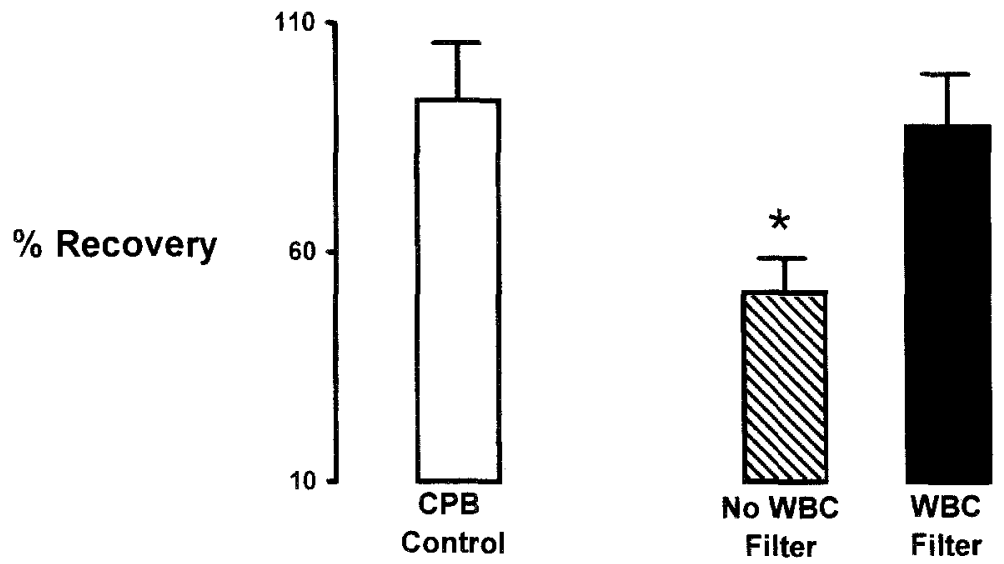

Hypoxia/Reoxygenation

Fig. 1. Percent recovery of $\mathrm{LV}$ end-systolic elastance (contractility) in piglets subjected to $\mathrm{CPB}$ without hypoxemia (CPB control) and those subjected to hypoxia followed by reoxygenation with CPB. No filter indicates those piglets that underwent reoxygenation without any attempt to reduce the number of neutrophils in the CPB circuit. WBC filter denotes those piglets reoxygenated with a leukocyte-depleting filter in the arterial line (see text for description). Note: There is almost complete preservation of LV systolic function in the CPB control and WBC filter groups. In contrast, the LV systolic elastance is significantly depressed if hypoxic piglets are reoxygenated without leukocyte filtration. ${ }^{*} p<0.0001$.

$\mathrm{PH}_{2} \mathrm{O}$ is partial pressure of water. PVRI and arterial/ alveolar ratio are expressed as a percentage of control.

Myocardial performance. $\mathrm{LV}$ pressure and conductance catheter signals were amplified and digitalized to inscribe LV pressure volume loops after first correcting for parallel conductance using hypertonic saline solution according to the method of Baan, Van Der Velde, and Steendijk. ${ }^{16}$ A series of pressure volume loops was generated under varying loading conditions by transient occlusion of the inferior vena cava during a 7-second period of apnea. The end-systolic and end-diastolic pressure volume relationship and preload recruitable stroke work index were analyzed with the use of a computer graphics program (Spectrum, Bowman Gray School of Medicine, Winston-Salem, N.C.) on a $486 / 33 \mathrm{MHz}$ Dell personal computer (Dell Computer Corp., Austin, Tex.). LV contractility was determined from the descending slope of the end-systolic pressure volume relationship by means of linear regression analysis and designated end-systolic elastance. End-diastolic compliance was determined from the exponential regression of the end-diastolic pressure volume relationship. Global myocardial performance was assessed by preload recruitable stroke work, which was calculated as the integral of LV transmural pressure and cavity volume over each cardiac cycle. Functional measurements are expressed as percent recovery of baseline values with each piglet acting as its own control.

Biochemical analysis. Myocardial tissue biopsies, taken from the LV, were immediately frozen in liquid nitrogen, crushed in a liquid nitrogen-cooled mortar and pestle, and lyophilized (Savant Speed Vac System, Farmingdale, N.Y.).

Adenosine triphosphate (ATP) was determined according to the method of Sarin and associates. ${ }^{17}$ Ten to fifteen milligrams of dry tissue was extracted with $0.6 \mathrm{~mol} / \mathrm{L}$ perchloric acid, the protein-free supernatant was neutralized by a mixture of $\mathrm{KHCO}_{3}$ in $0.5 \mathrm{~mol} / \mathrm{L}$ tromethamine (Tris) buffer ( $\mathrm{pH} 7.5)$, and the neutralized solution was allowed to stand at $4^{\circ} \mathrm{C}$ to precipitate $\mathrm{KCLO}_{4}$. Aliquots of the neutralized extract were analyzed with a high performance liquid chromatograph (Waters Inc., Milford, Mass.) equipped with a Waters Nova-Pak column. ATP was isocratically eluted with a mobile phase consisting of $0.1 \mathrm{~mol} / \mathrm{L}$ ammonium phosphate $(5.0 \mathrm{mmol} / \mathrm{L})$ tetrabutylammonium hydroxide ( $\mathrm{pH} \mathrm{5)}$, detected at $254 \mathrm{~nm}$, and expressed as micrograms per gram dry tissue.

Myocardial antioxidant state was assessed according to the method of Godin and Garnett ${ }^{18}$ by determining in vitro lipid peroxidation in cardiac tissue that was homogenized and incubated with 5-butyl hydroperoxide at a concentration of $4 \mathrm{mmol} / \mathrm{L}$ for 15 minutes at $37^{\circ} \mathrm{C}$. Lipid peroxidation was determined by measuring thiobarbituric acid reactive substances spectrophotometrically at 532 nm. A standard curve is run simultaneously and lipid peroxidation is expressed as nanomoles malondialdehyde per gram of heart tissue. Ten to fifteen milligrams of dry tissue was homogenized at $4^{\circ} \mathrm{C}$ in $1.75 \mathrm{ml}$ of $0.5 \mathrm{~mol} / \mathrm{L}$ tromethamine buffer, $0.1 \mathrm{mmol} / \mathrm{L}$ ethylenediaminetetraacetic acid, $\mathrm{pH}$ 7.6. Aliquots of the particle-free homogenate were incubated with $4 \mathrm{mmol} / \mathrm{L}$-butyl hydroperoxide for 30 minutes at $37^{\circ} \mathrm{C}$. The mixture was deproteinized with an equal volume of $28 \%$ of trichloroacetic acid containing $0.1 \mathrm{~mol} / \mathrm{L}$ sodium arsenite. Malondialdehyde in the protein-free supernatant was determined by heating in boiling water for 15 minutes with $0.5 \%$ thiobarbituric acid in $0.025 \mathrm{~mol} / \mathrm{L}$ sodium hydroxide and the color read at $532 \mathrm{~nm}$. 


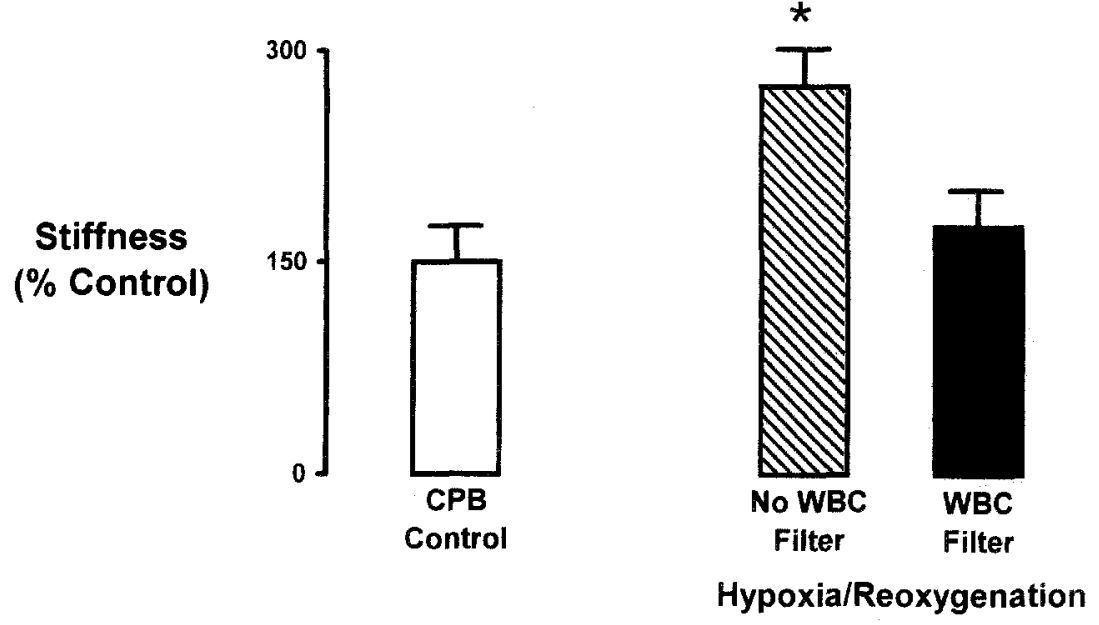

Fig. 2. Diastolic compliance measured by the exponential regression of the end-diastolic pressure volume relationship and expressed as percent stiffness compared with baseline. The lower the percentage the more compliant the ventricle and the higher the percentage the stiffer or less compliant the ventricle. The three groups are the same as listed in Fig. 1. Note: There is only a minimal rise in diastolic stiffness in nonhypoxic bypass control and hypoxic piglets reoxygenated with a WBC filter. In contrast, there was a marked rise in diastolic stiffness in hypoxic piglets undergoing reoxygenation without a WBC filter. ${ }^{*} p<0.0001$.

\section{Experimental groups}

$C P B$ without hypoxemia. Six normoxic piglets (CPB controls) underwent 90 minutes of CPB at a $\mathrm{PO}_{2}$ of 400 to $500 \mathrm{~mm} \mathrm{Hg}\left(\mathrm{FiO}_{2} 100 \%\right)$ without preceding hypoxemia to distinguish the effects of CPB alone.

Ventilator hypoxia. Hypoxia was imposed in 15 piglets by lowering the ventilator $\mathrm{FiO}_{2}$ to $8 \%$ to $10 \%$, producing an arterial $\mathrm{PO}_{2}$ of 25 to $30 \mathrm{~mm} \mathrm{Hg}$ and an oxygen saturation of $65 \%$ to $70 \%$. Before hypoxemia, piglets were given transfusions as necessary to raise the hematocrit to a value over $35 \%$. This condition simulates the chronic adaptive change of erythrocytosis that occurs in the cyanotic infant and increases oxygen-carrying capacity, thereby allowing ischemia to be avoided during hypoxia. Hypoxemia was maintained for 60 minutes, and during this time all animals remained in hemodynamically stable condition.

Reoxygenation protocol. After hypoxia all animals were supported with $\mathrm{CPB}$ at a $\mathrm{PO}_{2}$ of 400 to $500 \mathrm{~mm} \mathrm{Hg}\left(\mathrm{FiO}_{2}\right.$ $100 \%$ ) for 90 minutes. Nine piglets (group 1) underwent reoxygenation with no alternation in the CPB circuit, and six (group 2) underwent reoxygenation with a leukocytedepleting filter (BC-1, Pall Biomedical Products Corporation, Glencoe, N.Y.) inserted in the arterial bypass line.

Statistics. Data were analyzed with the use of JMP V2.0 (SAS Institute, Inc., Cary, N.C.) on a Macintosh IIVX computer (Apple Inc., Cupertino, Calif.). Paired Student's $t$ test was used for comparison of variables among experimental groups at the probability level of $p<0.05$. Group data are expressed as mean \pm standard error of the mean.

\section{Results}

No difference between groups was noted for control (baseline) values of LV contractility (endsystolic elastance $34 \pm 4)$, compliance $(0.04 \pm 0.01)$, or preload recruitable stroke work (76 \pm 4$)$; arterial/ alveolar ratio (0.92 \pm 0.02$)$; PVRI $(275 \pm 27$ dynes $\left./ \mathrm{sec} / \mathrm{cm}^{-5} / \mathrm{m}^{2}\right)$; or total WBC count $(5.2 \pm 0.6$ $\times 10^{3}$ cells $\left./ \mathrm{min}^{3}\right)$. Hypoxia resulted in an increase in heart rate from 130 to 150 beats/min to 180 to 200 beats/min, decreased systemic vascular resistance index, increased PVRI, and did not significantly affect cardiac output. All piglets tolerated $60 \mathrm{~min}$ utes of hypoxia with stable hemodynamics.

Postbypass hemodynamic and pulmonary function. Results are shown in Figs. 1 to 3. There was no change in the $\mathrm{X}$ intercept $\left(\mathrm{V}_{\mathrm{O}}\right)$ for end-systolic elastance or preload recruitable stroke work between prebypass (control) and postbypass values in any experimental group. Therefore the change in slope of end-systolic elastance, preload recruitable stroke work, and diastolic compliance can be interpreted to express variability in the contractile state of the myocardium compared with control values. CPB alone for 90 minutes (CPB controls) did not substantially change LV end-systolic elastance (93\% $\pm 6 \%)$, diastolic compliance $(150 \% \pm 10 \%)$, preload recruitable stroke work $(98 \% \pm 4 \%)$, or arterial/alveolar ratio $(97 \% \pm 6 \%$ ) from control (baseline) levels, but CPB did significantly raise PVRI (302\% $\pm 41 \% ; p<0.0001$ vs baseline). Reoxygenation of hypoxic hearts with CPB but without a leukocyte filter (group 1) decreased LV end-systolic elastance $(52 \% \pm 2 \%$ vs $93 \% \pm 6 \% ; p<0.0001)$, 


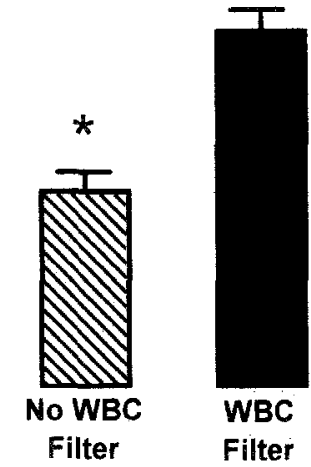

Hypoxia/Reoxygenation

Fig. 3. Overall LV myocardial function as measured by preload recruitable stroke work and expressed as a percentage of baseline. The three groups are the same as listed in Fig. 1. Note: There is almost complete preservation of global LV performance in nonhypoxic bypass control and hypoxic piglets reoxygenated with a WBC filter. Conversely, there is marked depression of overall LV function in hypoxic piglets reoxygenated without WBC depletion. ${ }^{*} p<0.0001$.

diastolic compliance $(275 \% \pm 8 \%$ vs $150 \% \pm 10 \%$ $p<0.0001)$, preload recruitable stroke work $(54 \% \pm$ $3 \%$ vs $98 \% \pm 4 \% ; p<0.0001)$, arterial/alveolar ratio $(74 \% \pm 5 \%$ vs $97 \% \pm 6 \% ; p<0.0001)$, and caused a further rise in PVRI $(391 \% \pm 45 \%$ vs $302 \% \pm 41 \%$; $p=0.04$ ) compared with CPB without hypoxia (CPB controls). Conversely, placing a leukocyte filter in the $\mathrm{CPB}$ arterial line (group 2) prevented the negative effects of reoxygenation and preserved LV contractility $(88 \% \pm 5 \%$ vs $52 \% \pm 2 \% ; p<0.0001)$, diastolic compliance $(175 \% \pm 9 \%$ vs $275 \% \pm 8 \% ; p<0.0001)$, global myocardial function $(91 \% \pm 4 \%$ vs $54 \% \pm 3 \%$; $p<0.0001)$, arterial/alveolar ratio $(97 \% \pm 3 \%$ vs $74 \%$ $\pm 5 \% ; p=0.0001$ ), and resulted in the lowest PVRI $(229 \% \pm 12 \%$ vs $391 \% \pm 45 \% ; p=0.001)$ compared with hypoxic piglets undergoing reoxygenation without leukocyte filtration (group 1). These values (group 2) were not significantly different from results seen in animals undergoing $\mathrm{CPB}$ without hypoxia (CPB control).

WBC count. Prebypass total WBC count was $5.2 \pm 0.6 \times 10^{3}$ cells $/ \mathrm{mm}^{3}$, which was not statistically changed by hypoxemia. In the nonfiltered groups the WBC count fell slightly with the start of CPB $\left(4.7 \pm 0.3 \times 10^{3}\right.$ cells $\left./ \mathrm{mm}^{3}\right)$ and continued to decrease slowly to $2.9 \pm 0.2 \times 10^{3}$ cells $/ \mathrm{mm}^{3}$ by the end of 90 minutes of CPB. Conversely, if leukocyte depletion was used the total WBC count fell abruptly with the initiation of bypass to $1.9 \pm 0.4 \times 10^{3}$ cells $/ \mathrm{mm}^{3}$ ( $p=0.02$ vs nonfiltered piglets) and remained low during the entire 90 minutes of $\mathrm{CPB}$.
Total neutrophil count followed the same trend (Fig. 4), with the WBC-filtered group (group 2) maintaining a significantly lower neutrophil count during CPB. Neither total WBC nor neutrophil count was statistically different between piglets undergoing bypass alone (CPB control) and those undergoing hypoxia/reoxygenation without a WBC filter (group 1).

Myocardial tissue. Endocardial ATP levels in hearts subjected to bypass alone was $18.1 \pm 0.7 \mu \mathrm{g} / \mathrm{gm}$ dry tissue, which is not significantly different from control values for our laboratory. The ATP level fell slightly after hypoxia and reoxygenation to $15.4 \pm 0.8$ $\mu \mathrm{g} / \mathrm{gm}$ tissue. In contrast, this reduction was prevented by use of a WBC filter during reoxygenation (18.7 \pm $1.0 \mu \mathrm{g} / \mathrm{gm} ; p=0.03$ vs hypoxia/reoxygenation). Antioxidant reserve capacity (Fig. 5) was unaffected by $\mathrm{CPB}$ alone because the results in this group are not statistically different from laboratory control values. Conversely, reoxygenation of the hypoxemic heart resulted in significant depletion of endogenous tissue antioxidants, indicating an oxidant stress had occurred during reoxygenation. This depletion was prevented by reoxygenating the hypoxemic heart with a leukocyte filter (Fig. 5).

\section{Discussion}

An increasing number of infants with cyanotic congenital heart disease are undergoing primary repair. Although this may be preferable to palliation, it subjects the heart to CPB and high oxygen 


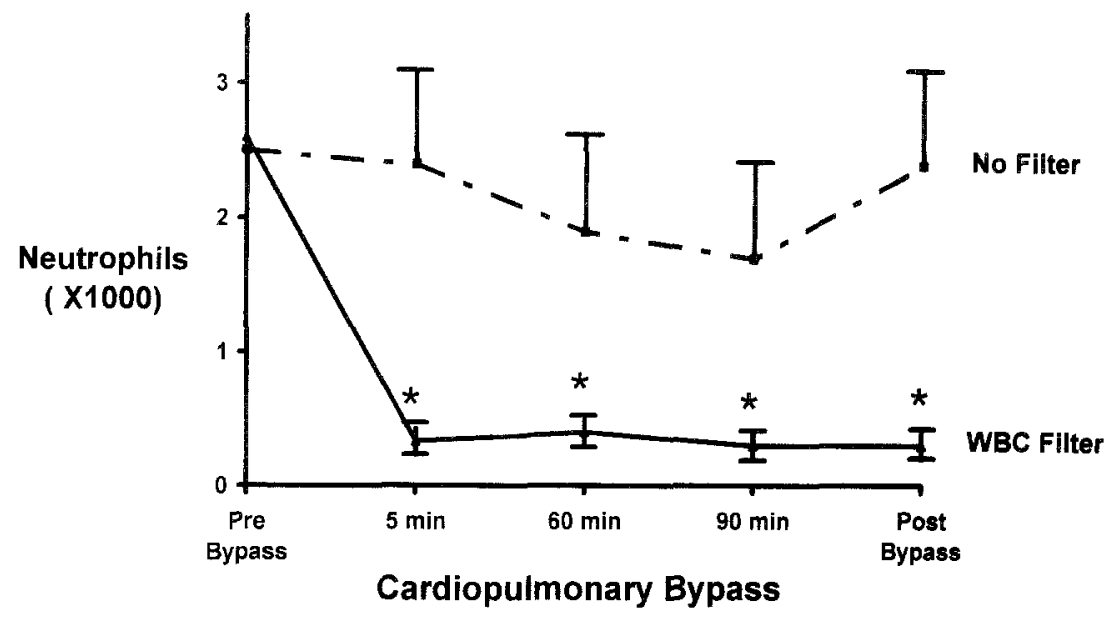

Fig. 4. Total neutrophil count in piglets undergoing CPB with and without a WBC filter. Note: The neutrophil count fell rapidly and remained low during the entire period of CPB when a leukocyte depletion filter was used. * $p<0.001$.

levels. Recent clinical and experimental studies indicated that an unintended reoxygenation injury, resulting from oxygen radicals, occurs when the acutely hypoxic piglet or chronically cyanotic infant is subjected to abrupt reoxygenation during CPB. ${ }^{3,6-9}$ This study supports these findings, because piglets reoxygenated after 60 minutes of hypoxemia (group 1) exhibited decreased LV contractility, compliance, and global myocardial performance; impaired oxygenation; and increased pulmonary vascular resistance (Figs. 1 to $5)$.

Activated leukocytes have been shown to play a major role in the generation of oxygen-derived free radicals after ischemia. ${ }^{10-13,19}$ Therefore it seems likely that they are also active in the reoxygenation injury, because both ischemia and hypoxia subject tissue to low levels of oxygen. $7,9,13,20,21$ Our data support this hypothesis. When neutrophils were reduced by a leukocyte-depleting filter (group 2), the detrimental effects of sudden reoxygenation were obviated, resulting in preservation of LV contractility and global myocardial performance, improved LV compliance, maintenance of oxygenation, and the smallest rise in pulmonary vascular resistance (see Figs. 1 to 3). Indeed the increase in pulmonary vascular resistance in these piglets (group 2) was even less than in animals subjected to CPB alone (CPB controls), suggesting that leukocyte filtration should be used in all pediatric operations in which postoperative pulmonary hypertension could be problematic. Although the rise in pulmonary vascular resistance may be due to numerous factors, it seems evident that reoxygenation and WBCs play a major role because (1) reoxygenated unfiltered piglets have the largest rise in pulmonary vascular resistance, (2) this rise is offset by leukocyte depletion during reoxygenation, and (3) other studies have demonstrated reduced lung injury and lower pulmonary pressures with leukocyte depletion. ${ }^{22}$

Neutrophils have a variety of deleterious effects. ${ }^{10-13,19}$ Under conditions of hypoxemia or ischemia, coronary vascular endothelium expresses sites that bind neutrophils on reperfusion. ${ }^{11,13,23}$ Once bound, the neutrophil may be activated by several different pathways, including superoxide production by xanthine oxidase, compliment activation, and leukotriene production. The bound activated neutrophil is then involved in pathways that contribute to myocyte injury. NADPH oxidase on the surface of neutrophils produces superoxide anions, hydroxyl radicals, and hypochlorous acid. ${ }^{23,24}$ Hypochloric is directly cytotoxic and activates proteases that destroy cellular structures. Neutrophils may also result in mechanical obstruction of capillaries, thereby preventing reperfusion to the distal areas of the myocardium. ${ }^{13,25}$ Activated neutrophils have been shown to depress calcium transport by the sarcoplasmic reticulum by oxygen-derived free radical injury and to significantly depress calciumstimulated magnesium-dependent ATP activity., 10, 24 In addition, lipid peroxidation of cellular membranes by toxic oxygen species liberated by WBCs disrupts cellular homeostatic mechanisms, resulting in intracellular edema. Oxidation of arachidonic acid contained 


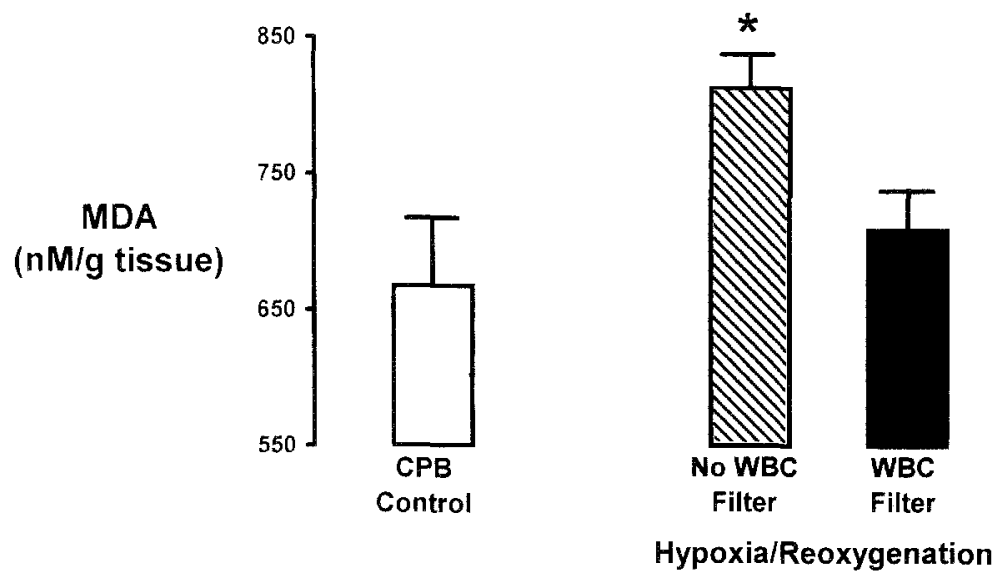

Fig. 5. Antioxidant reserve capacity in LV muscle sampled 60 minutes after CPB was discontinued in piglets undergoing CPB alone, or hypoxia and reoxygenation with and without a leukocyte-depleting filter. The more malondialdehyde $(M D A)$ produced when $4 \mathrm{mmol} / \mathrm{L}$ of the strong oxidant $t$-butyl hydroperoxide is added, the lower the amount of endogenous oxygen radical scavengers left in the tissue, indicating a previous oxidant stress resulting from oxygen-derived free radicals. Note: Compared with CPB alone, there is increased malondialdehyde production in hypoxic piglets reoxygenated without a WBC filter, indicating a greater exposure of the myocardial tissue to oxygen-derived free radicals. In contrast, this depletion of endogenous oxygen radical scavengers is prevented by the use of a WBC filter, indicating that WBCs are responsible for the generation of a large amount of oxygen radicals during reoxygenation. ${ }^{*} p=0.03$.

in cellular membranes results in the liberation of leukotrienes, prostaglandins, and thromboxanes, many of which are harmful and some of which are chemotactic for other neutrophils and macrophages, resulting in an amplification of the inflammatory response. ${ }^{23,24}$

In this study WBC filtration reduced leukocytes during the entire CPB period (see Fig. 4). Besides the injury activated WBCs cause, they also bind to activated platelets. Therefore, by removing activated platelets, a WBC filter may also help prevent the adverse effects of platelets, such as thromboxane release and vasoconstriction. ${ }^{12,13,23,25}$ In addition, because activated WBC/platelet complexes are larger, they should be more likely to be trapped by a filter. Therefore, even though the neutrophil count was not reduced to 0 , it is probable that very few activated WBCs escaped filtration.

Although WBCs can injure tissue by several mechanisms, numerous studies have demonstrated that production of oxygen radicals is probably the major factor responsible for cellular damage. ${ }^{11,12,24,26-28} \mathrm{To}$ investigate this phenomenon we determined the myocardial antioxidant reserve capacity at the end of the experiment. This test is done by adding a strong oxidant ( $t$-butyl hydroperoxide) to myocardial tissue. The test measures the tissue's ability to scavenge the resulting oxygen radicals and prevent malondialdehyde formation (a by-product of lipid peroxidation).
Therefore it tests the endogenous stores of oxygen radical scavengers. A loss of tissue antioxidants occurs when oxygen-derived free radicals are produced and need to be scavenged, such as when the hypoxemic heart undergoes abrupt reoxygenation during $\mathrm{CPB}$ (see Fig. 5). Conversely, the depletion of endogenous antioxidant stores seen in hypoxic reoxygenated hearts is prevented by WBC filtration. This implies that activated neutrophils are a major source of the oxygen radicals produced as a consequence reoxygenation and, inasmuch as postbypass ventricular and pulmonary function directly correlate with oxygen reserve capacity, confirms that a major component of the reoxygenation injury responsible for organ dysfunction is oxygen radicals.

Further support that a mechanism other than ischemia is responsible for producing this injury is derived from the ATP analysis. First, our model of acute hypoxia does not significantly deplete ATP levels. Furthermore, although the ATP levels were lower in hypoxic piglets after reoxygenation, indicating some cellular damage, they were only slightly reduced. In contrast, severe ATP depletion would have been expected had this injury been due to ischemia instead of another mechanism, such as an oxidant stress.

Critique of experimental model. The advantages of the intact animal model have been enumerated 
previously. ${ }^{29}$ Piglets aged 5 to 18 days approximate the physical conditions of a human neonate, but differences between the piglet and the newborn infant must still be evaluated. An important shortcoming of the short-term or acute hypoxic model is the absence of the ability to develop compensatory adaptive mechanisms. However, the postreoxygenation changes seen after acute hypoxemia parallel those reported in cyanotic patients who undergo reoxygenation during $\mathrm{CPB} .{ }^{2,8,9,22}$ Furthermore, using the same biochemical marker as in this study, we recently reported an identical oxidant injury in 28 infants. ${ }^{30}$ We administered transfusions to piglets before hypoxia to simulate the chronic adaptive change of erythrocytosis and have noted that coronary blood flow triples during acute hypoxia. Both of these factors increase oxygen delivery, thereby allowing ischemia to be avoided during acute hypoxia, as demonstrated by maintenance of oxygen consumption, lack of lactate production, and preservation of ATP levels (unpublished data). In contrast, the chronically cyanotic infant is predisposed to accelerated depletion of ATP, which may exacerbate the susceptibility not only to a reoxygenation injury but also to an ischemic injury. ${ }^{2,3,6}$ We examined only changes in the heart and lungs. However, inasmuch as oxygen radicals are generated systemically, it is almost certain that tissue damage occurred in other organs. Last, several studies have demonstrated the beneficial effects of leukocyte depletion in both the experimental and clinical settings. ${ }^{10,13,22}$ A recent article by Komai and coworkers, ${ }^{22}$ in which only the donor blood was filtered before CPB, documents the benefits of even partially removing leukocytes in preventing oxygen radical damage and subsequent lung injury in cyanotic and pulmonary hypertensive infants. Therefore, despite the shortcomings of this acute hypoxic model, it seems likely that the beneficial effects observed in this study will be seen if leukocyte depletion is used clinically. The avoidance of this injury could be especially important in lesions such as hypoplastic left heart, where any myocardial damage could have severe consequences. Indeed, a reoxygenation injury may help explain why myocardial function is often depressed in cyanotic infants despite apparently technically successful operations. ${ }^{1,2}$

In conclusion, this study demonstrates that (1) the hypoxic neonatal myocardium undergoes an unintended reoxygenation injury during reintroduction of molecular oxygen, (2) a major portion of this damage is caused by oxygen-derived free radicals,
(3) a predominant source of these oxygen-derived free radicals is the polymorphonuclear neutrophil, and (4) the reoxygenation injury can therefore be minimized through the use of a leukocyte-depleting filter, resulting in preservation of myocardial and pulmonary function. On the basis of this study we now use some form of leukocyte filtration in all our pediatric patients, considering it especially important in those who are hypoxemic. We believe that leukocyte depletion is a readily available method that allows the surgeon to safely minimize the harmful effects of neutrophils. It avoids the side effects of pharmacologic interventions aimed at altering leukocyte function or preventing the free radical injury through the use of exogenous oxygen radical scavengers.

\section{REFERENCES}

1. Rocchini AP, Keane JF, Castaneda AR, Nadas AS. Left ventricular function following attempted surgical repair of tetralogy of Fallot. Circulation 1978;57:798-802.

2. Del Nido PJ, Mickle DAG, Wilson GJ, Benson LN, Weisel $\mathrm{RD}$, Coles JG, et al. Inadequate myocardial protection with cold cardioplegic arrest during repair of tetralogy of Fallot. J Thorac Cardiovasc Surg 1988;95:223-9.

3. Hammon JW Jr. Myocardial protection in the immature heart. Ann Thorac Surg 1995;60:839-42.

4. Castaneda AR, Jonas RA, Mayer JE Jr, Hanley FL. Myocardial preservation in the immature heart. In: Castaneda $A R$, Jonas RA, Mayer JE Jr, Hanley FL, editors. Cardiac surgery of the neonate and infant. Philadelphia: WB Saunders; 1994. p. $41-54$

5. Jarmakani JM, Graham TP, Canent RV, Jewett PH. Left heart function in children with tetralogy of Fallot before and after palliative or corrective surgery. Circulation 1972;46:47890.

6. Silverman N, Kohler J, Levitsky S, Pavel D, Fang R, Feinberg $H$. Chronic hypoxemia depresses global ventricular function and predisposes to the depletion of high-energy phosphates during cardioplegic arrest: implications for surgical repair of cyanotic congenital heart defects. Ann Thorac Surg 1984;37: 304-8.

7. Buckberg GD. Studies of hypoxemic/reoxygenation injury. I Linkage between cardiac function and oxidant damage. J Thorac Cardiovase 1995;110:1164-70.

8. Teoh KH, Mickle DAG, Weisel RD, Li R, Tumiati LC, Coles JG. Effect of oxygen tension and cardiovascular operations on the myocardial antioxidant enzyme activities in patients with tetralogy of Fallot and aorta-coronary bypass. J Thorac Cardiovasc Surg 1992;104:159-64.

9. Del Nido PJ, Mickle DAG, Wilson G, Benson LN, Coles JG, Trusler GA, et al. Evidence of myocardial free radical injury during elective repair of tetralogy of Fallot. Circulation 1987;76(Suppl):V174-9.

10. Breda MA, Drinkwater DC, Laks H, Bhuta S, Corno A. Prevention of reperfusion injury in the neonatal heart with leukocyte-depleted blood. J Thorac Cardiovasc Surg 1989;97: 654-65.

11. Fantone $J$, Ward P. Role of oxygen-derived free radicals and 
metabolites in leukocyte-dependent inflammatory reactions. Am J Pathol 1982;107:394-418.

12. Mullane K, Read N, Salmon J, Moncada S. Role of leukocyte in acute myocardial infarction in anesthetized dogs: relationship to myocardial salvage by anti-inflammatory drugs. Circ Res 1983;53:584-91.

13. Byrne J, Appleyard R, Lee C, et al. Controlled reperfusion of the regionally ischemic myocardium with leukocyte-depleted blood reduces stunning, the no-reflow phenomenon, and infarct size. J Thorac Cardiovasc Surg 1992;103:66-72.

14. Friedman WF. The intrinsic physiologic properties of the developing heart. Prog Cardiovasc Dis 1972;15:87-111.

15. Romero TE, Friedman WF. Limited left ventricular response to volume overload in the neonatal period: a comparative study with the adult animal. Pediatr Res 1979;13:910-5.

16. Baan J, Van Der Velde E, Steendijk P. Ventricular pressure volume relations in vivo. Eur Heart J 1992;13(Suppl E):2-6.

17. Sarin M, Buinevicius Z, Levitsky. S, Feinberg H. Isocratic high-performance liquid chromatographic analysis of myocardial creatine phosphate and adenine nucleotides. J Chromatogr 1991;563:129-33.

18. Godin D, Garnett M. Altered antioxidant status in the ischemic/reperfused rabbit myocardium: effects of allopurinol. Can J Cardiol 1989;5:365-71.

19. Grisham M, McCord J. Chemistry and cytotoxicity of reactive oxygen metabolites. J Am Physiol Soc 1987:1-18.

20. Ihnken K, Morita K, Buckberg GD, Sherman MP, Young HH. Studies of hypoxemic/reoxygenation injury: without aortic clamping. III. Comparison of the magnitude of damage by hypoxemia reoxygenation versus ischemia/reperfusion. J Thorac Cardiovasc Surg 1995;110:1182-9.

21. Kraemer R, Mullane K. Neutrophils delay functional recovery of the post hypoxic heart of the rabbit. Pharmacol Exp Ther 1989;251:620-6.

22. Komai H, Yamamoto F, Tanaka K, Yagihara T, Kawashima Y. Prevention of lung injury during open heart operations for congenital heart defects. Ann Thorac Surg 1994;57:134-40.

23. Harlan J. Leukocyte-endothelial interactions. Blood 1985;65: $513-25$.

24. Rowe G, Manson N, Caplan M, Hess M. Hydrogen peroxide and hydroxyl radical mediation of activated leukocyte depression of cardiac sarcoplasmic reticulum: participation of the cyclooxygenase pathway. Circ Res 1983;53:584-91.

25. Engler R, Schmid-Schoebein G, Pavelec R. Role of leukocyte capillary plugging in preventing myocardial reperfusion. Circulation 1981;64(Suppl):IV138.

26. Jurmann M, Schaefers H, Dammenhayer L, Haverich A. Oxygen-derived free radical scavengers for amelioration of reperfusion damage in heart transplantation. $\mathrm{J}$ Thorac Cardiovasc Surg 1988;95:369-77.

27. Stewart J, Gerhardt E, Weber C. Free radical scavengers and myocardial preservation during transplantation. Ann Thorac Surg 1986;24:390.

28. Otani H, Engelman R, Ronson J, Breyer R, Lemeshow S, Das D. Cardiac performance during reperfusion improved by pretreatment with oxygen free radical scavengers. J Thorac Cardiovase 1986;91:290-5.

29. Swindle N. Porcine models in surgical research: an overview. Tumbleson $\mathrm{M}$, editor. Swine in biomedical research. New York: Plenum Press. 1986. p. 235-41.

30. Allen BS, Rahman SK, Ilbawi M, Feinberg H, Bolling KS, Kronon M. The detrimental effects of cardiopulmonary by- pass in cyanotic infants: preventing the reoxygenation injury. Society of Thoracic Surgeons 1997; 33rd Annual Meeting: Abstract.

\section{Discussion}

Dr. Hillel Laks (Los Angeles, Calif.). I would also like to congratulate Dr. Bolling, Dr. Allen, and the rest of the group from the University of Illinois for their excellent study, which I think is preclinical in application. It has shown that ischemia and reperfusion and their effects can be ameliorated by leukocyte depletion of the reperfusate. The group from Johns Hopkins first demonstrated this in lung preservation. Our group showed that after 12 hours of neonatal piglet heart preservation, leukocyte-depleted reperfusion resulted in dramatic improvement in cardiac function. Increasing numbers of studies are showing that hypoxia with reoxygenation causes a similar type of injury, which is also mediated by leukocytes and by oxygenderived free radicals.

I have a question with regard to your leukocyte filters. We have found that with higher blood flows the ability of the filter to remove leukocytes is depleted and after a short while the leukocyte count rises. What system did you use to maintain these very low levels of WBCs from what I understand were around 300 during the course of CPB?

Dr. Bolling. No filter is ideal. We chose the Pall BC-1 filter because it was the most efficient leukocyte filter currently available. At flows of 500 to $600 \mathrm{ml} / \mathrm{min}$, the BC-1 filter removes most WBCs in the first pass. These flows were adequate for our 4 to $5 \mathrm{~kg}$ piglet model, and we kept the filter in the CPB circuit for 90 minutes without complications. However, WBC filters are flow dependent, and you are correct that these filters are less efficient if higher flows are used. In addition, the $\mathrm{BC}-1$ filter can be used only at flows up to approximately $700 \mathrm{ml} / \mathrm{min}$. Therefore, in bigger children, an LG-6 filter would be needed, because it can be used at flows up to $6 \mathrm{~L} / \mathrm{min}$. This filter is less efficient at removing WBCs during the first pass and instead removes neutrophils slowly over time. However, inasmuch as this filter is also flow dependent, it is fairly efficient at lower flow rates. Therefore it may still be effective in infants. In contrast, no good arterial leukocyte-depleting filter is available for larger children. Because the reoxygenation injury probably occurs early, complete removal of WBCs is important during the initial reintroduction of oxygen. On the basis of our results, we now use the BC-1 filter in patients weighing less than $4 \mathrm{~kg}$. We have used it without problems, although we have been removing it 30 to 60 minutes after initiating CPB because of concerns that we may develop an increased pressure across the filter. We also use a Pall RC- 400 filter to remove WBCs from any blood added to the bypass circuit, because this has similarly been shown to lower pulmonary pressures in cyanotic infants.

Dr. Laks. Have you found in the clinical situation that the WBC counts have remained low with use of the BC-1 filter?

Dr. Bolling. Yes, we have. We have now used the BC-1 filter clinically in six neonates and have had extremely low neutrophil counts in all cases.

Dr. Laks. My second question concerns the issue of the clinical relevance of your model with acute hypoxia for 60 
minutes to the clinical setting. It certainly is relevant for patients who will have extracorporeal membrane oxygenation after periods of acute hypoxia. Is it relevant for patients with chronic cyanosis as opposed to acute hypoxia? Silverman and Levitsky observed a reduced ability of the heart to withstand a period of ischemia after chronic hypoxia. Is there also a reoxygenation injury occurring in chronically cyanotic patients when they are exposed to reoxygenation?

Dr. Bolling. The reoxygenation changes occurring after acute hypoxia have been reported by several authors in cyanotic infants undergoing corrective operations. Other studies have documented myocardial dysfunction in hypoxic infants undergoing $\mathrm{CPB}$ or extracorporeal membrane oxygenation. This dysfunction is similar to the myocardial depression seen in hearts after acute hypoxia. Dr. Komai and his group also demonstrated decreased pulmonary vascular resistance and improved lung function with partial depletion of neutrophils in cyanotic infants undergoing operative repair. This further supports the clinical relevance of our acute hypoxic model, as well as the benefits of limiting neutrophils in hypoxic infants. We therefore believe there is ample clinical evidence that a reoxygenation injury does exist and can be prevented by means of WBC filtration.

Dr. Laks. This study suggests that we should all begin to use the leukocyte-depleting filter clinically. However, another modality is available to prevent reoxygenation injury at the start of CPB. We have begun clinically to reduce the degree of oxygenation in the oxygenator to achieve a $\mathrm{Po}_{2}$ of 80 to $100 \mathrm{~mm} \mathrm{Hg}$ at the start of bypass rather than the usual 300 to $400 \mathrm{~mm} \mathrm{Hg}$ in hypoxic patients. We have also been using the leukocyte-depleting filter for our cardioplegia in the infant group. As Dr. Bolling and his colleagues have shown, the leukocytedepleting filter should be considered for the bypass circuit for hypoxic infants.

Dr. Bolling. We agree that decreasing the $\mathrm{FiO}_{2}$ of the CPB circuit to $21 \%$ may help limit the reoxygenation injury, and we are currently conducting a study to investigate this intervention. Although preliminary data suggest that the reoxygenation injury can be limited by either decreasing the $\mathrm{FiO}_{2}$ to $21 \%$, or neutrophil depletion, use of a leukocyte filter appears to be more important.

\section{ON THE MOVE?}

Don't miss a single issue of the journal! To ensure prompt service when you change your address, please photocopy and complete the form below.

Please send your change of address notification at least six weeks before your move to ensure continued service. We regret we cannot guarantee replacement of issues missed due to late notification.

JOURNAL TITLE:

Fill in the title of the journal here.

OLD ADDRESS:

Affix the address label from a recent issue of the journal here.

\section{NEW ADDRESS:}

Clearly print your new address here.

Name

Address

City/State/ZIP
COPY AND MAIL THIS FORM TO:

Journal Subscription Services

Mosby-Year Book, Inc.

11830 Westline Industrial Dr.

St. Louis, MO 63146-3318
OR FAX TO:

314-432-1158

N/ Mosby
OR PHONE:

1-800-453-4351

Outside the U.S., call

314-453-4351 